\title{
Fertilite Hemşireliğinde Güncel Uygulamalar: Dünya'dan Örnekler
}

\author{
Current Practices in Fertility Nursing: Examples from the World
}

\section{Merlinda Aluş TOKAT ${ }^{1}$, Sevcan FATA ${ }^{2}$}

1. Dokuz Eylül Üniversitesi, Hemşirelik Fakültesi, İzmir, Türkiye, Doç.Dr.

2. Dokuz Eylül Üniversitesi, Hemşirelik Fakültesi, İzmir, Türkiye, Arş.Gör.

Makale 16-18 Kasım 2016 tarihinde İzmir'de düzenlenen “IV. Hemşirelikte Güncel Yaklaşımlar ve Sorunlar Kongresi’nde poster bildiri olarak sunulmuştur ve "İzmir Katip Çelebi Üniversitesi Sağlık Bilimleri Fakültesi Dergisi”, "Hemşirelikte Güncel Yaklaşımlar Kongresi Ek Sayısı”nda poster bildiri başlı̆̆ı altında yer almıştır

\section{$\ddot{O Z Z T T}$}

Son yıllarda infertilitenin tedavi ve bakımında psikososyal yaklaşımlar giderek önem kazanmaktadır. Ülkemizde bu konuda önemli gelişmeler olsa da, kurumlarda psikososyal yaklaşımlar çok sistematik ve belli standartlar doğrultusunda uygulanmamaktadır. Dünya'da fertilite sorunu olan çiftlerle çalışan bazı kurumlar tedaviyi destekleyen benzer hemşirelik girişimlerini kurum politikası haline getirmiş ve her çifte uygulamaktadir. Royal College of Nursing (RCN)'de fertilite hemşireleri tanı ve tedavi sürecinde çiftlere düzenli psikososyal destek girişimleri uygulamaktadır. Boston In Vitro Fertilizasyon (IVF) merkezinde hemşireler fertilite desteği alan çiftlere tedavi ile paralel beyin-beden programı uygulamaktadır. Canada'da International Federation of Gyneacologic and Obstetrics (FIGO) tarafindan sağlık profesyonellerinin fertilite sorunu olan çiftlerde yaklaşımda izleyecekleri sistematik basamaklar geliştirilmiştir. Bunun dışında bazı kurumlarda hemşireler hipnofertilite ve fertilite yogası gibi yöntemler de uygulamaktadir. Bu gibi standartlarin bulunması çiftlerin kendilerine özgü bakım almasını sağlayacaktır.

Anahtar Kelimeler: hemşire, fertilite, güncel uygulamalar, uygulama örnekleri

\section{ABSTRACT \\ In recent years, psychosocial approaches in the treat- ment and care of infertility have become increasingly impor- tant. Although important developments are being made in this issue in our country, psychosocial approaches in institutions are not implemented systematically and in line with certain standards. Some institutions working with couples with fertility problems around the world have made similar nursing inter- ventions supporting the treatment as institutional policy and have implemented each couple. In Royal College of Nursing, fertility nurses practice regular psychosocial support interven- tions for couples during the diagnosis and treatment. In Bos- ton In Vitro Fertilization center, nurses have implemented bra- in-body program couples receiving fertility support to parallel treatment. In Canada, International Federation of Gynecologic and Obstetrics has developed systematic steps for health pro- fessionals to follow in couples with fertility problems. Nurses also apply methods such as hypnofertility and fertility yoga in some institutions. These standarts will allow couples to take individual care.}

Keywords: nurse, fertility, current practices, practice pattern

iletişim:

Sorumlu Yazar: Sevcan FATA

Adres: Dokuz Eylül Üniversitesi, Hemşirelik Fakültesi, Bahçelerarası Mahallesi, Haydar Aliyev Bulvarı, Balçova, 35340, İzmir Tel: +90 (232) 4126975

E-Posta: sevcan_fata@hotmail.com

Makale Geliş: 08.01.2018

Makale Kabul: 07.04.2018

DOI: http://dx.doi.org/10.16948/zktipb.376189

\section{Gİiș}

Sıklı̆̆g giderek artan infertilite, çiftlerin biyopsikososyal sağlığını bozan bir tablodur (1-8). Uzun yıllardır infertilitenin tedavi ve bakımında özellikle ülkemizde temel odak noktası fizyolojik kısmı olsa da, artık psikososyal yönü de giderek önem kazanmaktadir.

Ülkemizde bu konuda önemli gelişmeler mevcut, fakat kurumlarda psikososyal yaklaşımlar çok sistematik ve belli standartlar doğrultusunda uygulanmamaktadır. Bu alanda çalıșan hemşirelerin güncel bilgi ve donanımını sağlamak için "Üreme Sağlığı ve İnfertilite Hemşireliği Derneği" ve "İnfertilite Hemşireliği Derneği” tarafından sempozyumlar/ eğitimler düzenlenmektedir. Fakat eğitimler tüm fertilite hemşirelerine ulaşmamakta, ulaştığı durumlarda da merkezin veya kurumun politikası nedeniyle hemșirelerin girișimleri her çifte uygulaması mümkün olmamaktadır. Çiftlere bütüncül yaklașımı sağlamak için dünyada bazı kurumlar hemşirelik girişimlerini kurum politikası haline getirmiş ve her çifte uygulamaktadır.

Bu derlemenin amacı Dünya'dan örneklerle fertilite hemşireliğine ilişkin güncel uygulamaları incelemektir.

\section{Dünya'dan Fertilite Hemşireliği Uygulamaları- na İlișkin Güncel Örnekler}

Bu derlemede "Royal Hemşirelik Koleji (Royal College of Nursing) (RCN)", "Boston In Vitro Fertilizasyon (IVF) Merkezi", "Uluslararas1 Obstetri ve Jinekoloji Birliği Uluslararası Obstetri ve Jinekoloji Birliği (International Federation of Gyneacologic and Obstetrics) (FIGO)" gibi kuruluşların örnekleri ile "Hipnofertilite" ve "Fertilite Yogası" uygulama örnekleri incelenmiştir.

\section{Royal Hemşirelik Koleji Örneği}

RCN'de Ebeler ve Fertilite Hemşireleri grubu tarafından geliştirilen kavramsal çerçeve ile İngiltere çapındaki, farklı yetkinlik düzeyleri olan fertilite hemşirelerinin fertilite desteği alan çiftlere psikososyal yaklaşımda görev ve sorumlulukları standardize edilmiştir. 
$\mathrm{Bu}$ çerçeve fertilite hemşireliğinde yüksek bir bakım standardı sağlamak için hemşirelerin gerekli beceri ve bilgiye ulaşmalarını sağlamaktadir.

Yetkinlik düzeyleri; sağlık destek görevlileri, lisansl1, kayıtlı mezun hemşire (registered nurse), uzman hemşire, yüksek lisans/doktora düzeyinde hemșire ve danıșman/lider hemșire șeklinde sınıflandırılmıştır (9) (Tablo 1).

\section{Boston In Vitro Fertilizasyon Merkezi Örneği}

Boston IVF merkezinde çalışan hemşirelerin rolleri arasında çiftlerin psikolojik sorunlarını anlama, fertilite sorunu yaşayan çiftlerde en s1k rastlanan psikolojik sorunları bilme, bireysel bakım sağlama gibi roller yer almaktadır. Merkezde hemşireler tarafindan beden-beyin programı yürütülmektedir (10). Beyin-beden programı 10 bölümden oluşmaktadır (11) (Tablo 2).

\section{Uluslararası Obstetri ve Jinekoloji Birliği (FIGO) Örneği}

Kanada'da FIGO tarafindan sağlik profesyonellerinin fertilite sorunu olan çiftlere psikososyal yaklaşımda izleyecekleri sistematik basamaklar geliştirilmiştir. Psikososyal yaklaşımlar aşamasında çiftlerin fertilite desteği gereksinimini saptamak, kișisel ve sosyal sınırlarını belirlemek gibi aşamalar oluşturulmuştur (12) (Tablo 3).

\section{Hipnofertilite Örneği}

Bazı kurumlarda hemşireler hipnofertilite yaklaşımı kullanarak fertilite sorunu yaşayan çiftleri tanı ve tedavi sürecinde desteklemektedir $(13,14)$. Temel ilkesi, doğurganlığın doğal bir işlev olduğudur (15). Hipnofertilite güçlü ve etkili beyin-beden etkileșimine dayanmaktadır. Beyin bilinçli ya da bilinçsiz, küçüklüğümüzden bu yana tüm deneyimlerimizi ve dışarıdan alınan mesajları kaydetmektedir.

Tablo 1: Farklı Düzeylerdeki Fertilite Hemşirelerinin Psikososyal Destek Rolleri.

\begin{tabular}{|c|c|}
\hline Hemşire Yetkinlik Düzeyi & Psikososyal Destek Rolleri \\
\hline $\begin{array}{l}\text { Sağlık Destek Görevlileri (Health Care Support Worker) } \\
\text { Bağımsız rol almayan, eğitimleri ve aldıkları süpervizyonun dere- } \\
\text { cesine göre sınıflandırılan hemşire }\end{array}$ & $\begin{array}{l}\text { - Tüm hasta etkileşimlerinde mahremiyeti ve gizliliği sağlamak, } \\
\text { - } \quad \text { Duygusal desteğin ne zaman gerekli olduğunu saptamak ve gerekir- } \\
\text { se bir üst düzeydeki yetkiliye yönlendirmek. }\end{array}$ \\
\hline $\begin{array}{l}\text { Yetkili Hemşire (Competent Nurse, Registered Nurse) } \\
\text { Lisanslı, kayıtlı mezun hemşire }\end{array}$ & $\begin{array}{l}\text { "Sağlık Destek Görevlileri” rollerine ek; } \\
\text { - } \quad \text { Çiftlerin ihtiyaç ve bakımlarına uygun temel duygusal destek } \\
\text { sağlamak, } \\
\text { - } \quad \begin{array}{l}\text { İnsan Fertilizasyonu ve Embriyoloji Kurumu tarafından organize } \\
\text { edilen danışmanlık kurslarından sertifika almak, }\end{array} \\
\text { - } \quad \begin{array}{l}\text { Fertilite danışmanlığı ile ilgili olarak yerel ve ulusal destek kuruluş- } \\
\text { larından haberdar olmak. }\end{array}\end{array}$ \\
\hline $\begin{array}{l}\text { Tecrübeli/Yetkin Hemşire (Experienced/Proficient Nurse) } \\
\text { Lisans mezuniyeti sonrası alana ilişkin sertifika programı, 6-12 } \\
\text { aylık eğitim veya yüksek lisans programı tamamlamış hemşire }\end{array}$ & $\begin{array}{l}\text { "Yetkili Hemşire" rollerine ek; } \\
\text { - } \quad \begin{array}{l}\text { Tanı, tedavi ve takipler sırasında çiftleri duygusal olarak destekle- } \\
\text { mede uygun kişilerarası iletişim becerilerini kullanmak, }\end{array} \\
\text { - } \quad \begin{array}{l}\text { Diğer sağlık ekibi üyelerinden danışmanlık almayı gerektiren du- } \\
\text { rumları fark etmek, }\end{array} \\
\text { - Yönlendireceği kurumlara karar vermek. }\end{array}$ \\
\hline $\begin{array}{l}\text { İleri Uygulama/Uzman Hemşire (Senior Practitioner/Expert } \\
\text { Nurse/Advanced Nurse Practitioners) } \\
\text { Yüksek lisans/doktora derecesi olan hemşire }\end{array}$ & $\begin{array}{l}\text { “Tecrübeli / Yetkin Hemşire” rollerine ek; } \\
\text { - Karmaşık durumlarda kendinden alt düzeydeki hemşirelere destek } \\
\text { sağlamak, } \\
\text { - } \quad \text { En üstü düzeydeki kurumlardan tanınmış danışmanlık belgesine } \\
\text { sahip olmak. }\end{array}$ \\
\hline $\begin{array}{l}\text { Danışman/Lider Hemşire (Consultant Nurse) } \\
\text { Kritik analiz, problem çözme, stratejik karar verme becerisi ve } \\
\text { otonomi sahibi hemşire }\end{array}$ & $\begin{array}{l}\text { “İleri Uygulama/Uzman Hemşire” rollerine ek; } \\
\text { - } \quad \text { Birincil, ikincil ve üçüncül bakım verirken stratejik yönü belirle- } \\
\text { mek, } \\
\text { - } \quad \text { Bakıma özgü firsatları ve eksiklikleri belirlemek, } \\
\text { - } \quad \begin{array}{l}\text { Nitelikli ve yetkin bir işgücünü sağlamak için eğitim ve öğretim } \\
\text { firsatlarını (danışmanlı becerileri ile bağlantılı) belirlemek, }\end{array} \\
\text { - } \quad \begin{array}{l}\text { Infertilitede psikoloji/danışmanlık ile ilgili araştırmaları takip et- } \\
\text { mek, }\end{array} \\
\text { - Yerel araştırma firsatlarını desteklemek, } \\
\text { - Standart tedavi protokollerine ilişkin bağımsız danışmanlık hizmet- } \\
\text { lerini yönetmek. }\end{array}$ \\
\hline
\end{tabular}


Tablo 2: Domar Beyin-Beden Programının İçeriği.

\begin{tabular}{|c|c|}
\hline Bölüm & İçeriği \\
\hline 1. & $\begin{array}{l}\text { Bireyleri tanımak, stres-infertilite ilişkisi ile ilgili çalış- } \\
\text { maları sunmak, bireylerin gevşemeye uygunluğunu değer- } \\
\text { lendirmek, fertilite sorunu yaşayan çiftlerin aynı sorunu } \\
\text { yaşayan çiftlerle duygu, düşünce ve deneyimlerini paylaş- } \\
\text { masını sağlamak, programın içeriğini açılamak. }\end{array}$ \\
\hline 2. & $\begin{array}{l}\text { Diyafram solunumu, gevşeme egzersizleri, beyni olumlu } \\
\text { etkileme yollarını ögretmek. }\end{array}$ \\
\hline 3. & $\begin{array}{l}\text { Kişinin kendi kendini olumlu etkilemesini, yaşama sevin- } \\
\text { ci fark etmesini sağlamak. }\end{array}$ \\
\hline 4. & $\begin{array}{l}\text { Yaşam tarzının fertilite üzerindeki etkisini açıklamak; } \\
\text { kilo, beslenme, sigara içme, alkol, kafein ve egzersizin } \\
\text { fertilite üzerindeki etkisini açıklamak, alternatif tıp yakla- } \\
\text { şımlarının yarar ve zararlarını açıklamak. }\end{array}$ \\
\hline 5. & Yogaya giriş, yoga hareketlerini yaptırmak. \\
\hline 6. & $\begin{array}{l}\text { Bilişsel Terapi: Olumsuz düşüncelerin, kelimelerin vücu- } \\
\text { da etkisini fark etmek ve olumlu kelime ve düşüncelere } \\
\text { dönüştürmek. }\end{array}$ \\
\hline 7. & $\begin{array}{l}\text { Stresi azaltmak için mizahı kullanmak, ikili gruplar oluş- } \\
\text { turup birbirlerini dinlemelerini sağlamak, görselleştirme } \\
\text { kullanmak, kişinin yaşam tarzı haritasını oluşturmak. }\end{array}$ \\
\hline 8. & Bilişsel terapiye devam etmek. \\
\hline 9. & $\begin{array}{l}\text { Suçluluk, utanç, kızgınlık gibi duyguları kontrol altına } \\
\text { almayı ögretmek, fertilite sorunu yaşayan çiftlerin evlat } \\
\text { edinen ya da donör oosit ile gebe kalan bireylerle duygu, } \\
\text { düşünce ve deneyimlerini paylaşmasını sağlamak. }\end{array}$ \\
\hline 10. & $\begin{array}{l}\text { Kendine güvenmeyi, hedef belirlemeyi öğretmek, progra- } \\
\text { mı özetlemek, öneriler almak, programı bitirmek. }\end{array}$ \\
\hline
\end{tabular}

Beyin işlevsel olarak bilinç, bilinçaltı ve eleştirel faktörden oluşmaktadır. Bilinç, analiz yapan, mantık yürüten, gerçekliğin yer aldığı bölümdür. Bilinçte; kişisel sınırlar, tutumlar, inançlar, kararlar, gelecek umudu ve düşünceler yer almaktadır. Fertilite problemi yaşayan kadınlar infertil, başarısız, steril, tamamen başarısızlık, karmaşık, zor, disfonksiyon, bozukluk, hasar, eksiklik, çok geç gibi kelimeleri sik duymaktadırlar.

Bilinçaltı, bilgisayar gibi doğru ya da yanlış ayırmadan kabul eden, mantıklı düşünmeyen, yaratıcı, duygusal bölümdür. Bilinçaltımızda, duygular, davranışlar, deneyimler ve düşünce biçimi yer almaktadır. Fertilite problemi yaşayan kadınların bilinçaltında sıklıkla verimsiz, yetersiz, mutsuz gibi duygular yer almakta, tanı ve tedavi sürecinde olumsuz düşünce biçimini benimsemekte ve davranış olarak stres yaşamaktadırlar. Eleştirel faktör ise bilinç ve bilinçaltı arasında yer almaktadır. Bilinçli halimiz mesajları yargılamadan kabul etmez.

Bilinçaltımız da bunun aksine olumlu veya olumsuz tüm mesajları kabul eder. Eleştirel faktör bariyeri, Hipnofertilite ile devreye girer ve olumsuz mesajların bilinçaltına yerleşmesini engellerken olumlu mesajların yerleşmesini sağlar.

Tablo 3: FIGO Sağlık Profesyonellerinin Fertilite Sorunu Olan Çiftlere Psikososyal Yaklaşımda İzleyecekleri Aşamalar.

\begin{tabular}{|c|c|}
\hline Aşamalar & Girişimler \\
\hline $\begin{array}{l}\text { Fertilite } \\
\text { Desteği Ge- } \\
\text { reksinimini } \\
\text { Saptamak }\end{array}$ & $\begin{array}{l}\text { - Yaşam kalitesinin etkileme durumunu değer- } \\
\text { lendirmek, } \\
\text { İnfertilite durumunun bireye yükünü sapta- } \\
\text { mak, } \\
\text { - Tedavi konusunda politik yaklaşımları ve } \\
\text { bireyin durumunu değerlendirmek. }\end{array}$ \\
\hline $\begin{array}{l}\text { Kişisel Sınır- } \\
\text { ları Belirle- } \\
\text { mek }\end{array}$ & $\begin{array}{l}\text { - } \begin{array}{l}\text { Bakımı etkileyebilecek bireysel engelleri fark } \\
\text { etmek, }\end{array} \\
\text { - } \quad \text { Maliyet açıdan sınırları detaylı öğrenmek, } \\
\text { Tedavi merkezine ulaşma engellerini kaldır- } \\
\text { maya yardımcı olmak, } \\
\text { - } \quad \text { Ailesel/toplumsal engelleri tanımlamak, } \\
\text { - } \quad \begin{array}{l}\text { Ulaşılabilir teknolojik hizmetleri tanımlamak, } \\
\text { yardım kuruluşlarını tanımlamak, }\end{array} \\
\text { Testler ve tedavi için en uygun seçenekleri } \\
\text { belirlemek, } \\
\text { Bireyleri eğitmek. }\end{array}$ \\
\hline $\begin{array}{l}\text { Sosyal Sinır- } \\
\text { lar1 Belirle- } \\
\text { mek }\end{array}$ & 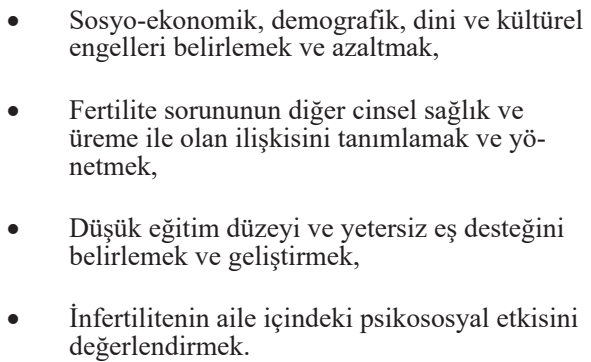 \\
\hline
\end{tabular}


Bilinci olumlu etkilemek için olumlu kelimeler kullanılmalıdır. Hipnofertilite yönteminde fertil, fertilite, üretken, verimli, yetenekli, sürdürülebilir, bol, olası, gelişen, iyileşen, umutlu gibi kelimeler yer almaktadır. Bunlar Hipnofertilite'de fertilitenin dili olarak geçmektedir. Bilinçaltı ise görselleştirme, gevşeme ve hayal etme gibi yöntemlerle olumlu etkilenebilmektedir (15).

Görselleştirme, kişinin, zihninde bir görsel yaratmasi ve isterse buna tat, koku ve sesi eklemesidir (16). Hayal etme, kişinin kendini, sakin, gevșemiş ve huzurlu hissedebileceği yer, olay ve zamanı hayal etmesidir (17). Gevșeme, kișinin vücudunu rahatlatmasıdır. Gevşemeler sırasında nefes egzersizleri, hayal kurma, görselleştirme, zihin alanı oluşturma ve müzik kullanılabilir (16).

\section{Fertilite Yogası Örneği}

Hemșireler tarafindan da uygulanan fertilite yogası oldukça stresli bir süreç olan infertilitede kadının rahatlamasını sağlamaktadır. Duygusal stres anında otonom sinir sistemi devreye girer ve sempatik sinir sistemi aktive olur, hipotalamusu bask1lar. Kana salınan GnRH azalır, ön hipofizden de LH ve FSH salınım1, overlerden östrojen ve progesteron salınımı azalır, üreme organlarına giden kan miktarı azalır (18-21).

Fertilite yogası ile çiftler hem fizyolojik hem de psikososyal olarak olumlu etkilenmektedir. Fertilite yogasındaki fiziksel hareketlerle üreme organlarına giden kan akımı artırılarak hormon salgısı, ovulasyon ve endometriyum kalınlığı olumlu yönde etkilenmektedir. Ayrıca fertilite yogası çiftlerin gevşemesini sağlayarak parasempatik sinir sistemini aktive ederek fertilite hormonlarının salınımını artırmaktadır (22). Böylece fertilite yogası hem fizyolojik ve hem de psikolojik yönde çiftleri desteklemiș olmaktadır.

\section{SONUÇ}

Hemșirelerin fertilite sorunu yaşayan çiftlerin bakımında sistematik, bütüncül ve bilgiye dayalı yaklaşımları kullanmasının çiftlerin stresini azaltmada, gebelik sonuçlarını artırmada ve hemșireye olan güven ve bakıș açısını değiștirmede etkili olacağı düşünülmektedir. Dünya örnekleri göz önüne alınarak ülkemizdeki infertilite merkezlerinde standart bakım protokolleri oluşturularak hem çiftlerin memnuniyetleri hem de tedavi sonuçları değerlendirilmelidir.

\section{KAYNAKLAR}

1. Klonoff-Cohen H, Chu E, Natarajan L \& Sieber W. A Prospective Study of Stress Among Women Undergoing in Vitro Fertilization or Gamete Intrafallopian Transfer. Fertility and Sterility 2001; 76(4): 675-687.

2. Güz H, Özkan A, Sarısoy G, Yanık F, Yanık A. Psychiatric symptoms in Turkish infertile women. Journal of Psychosomatic Obstetrics Gynaecology 2003; 24: 267-271.
3. Jedrzejczak P, Luczak-Wawrzyniak J, Szyfter J, Przewoźna J, Taszarek-Hauke G, et al. Feelings and emotions in women treated for infertility. Przeglad Lekarski 2004; 61: 1334-1337.

4. Schmidt L, Holstein BE, Christensen U \& Boivin J. Communication and Coping as Predictors of Fertility Problem Stress: Cohort Study of 816 Participants Who Did Not Achieve A Delivery After 12 Months of Fertility Treatment. Human Reproduction 2005; 20(11): 3248-3256.

5. Morreale M, Balon R, Tancer $M$ \& Diamond M. The Impact of Stress and Psychosocial Interventions on Assisted Reproductive Technology Outcome. Journal of Sex \& Marital Therapy 2010; 37(1): 56-69.

6. Matthiesen SMS, Frederiksen Y, Ingerslev HJ \& Zachariae R. Stress, Distress and Outcome of Assisted Reproductive Technology (ART): A Meta-Analysis. Human Reproduction 2011: 1 -14 .

7. Keskin G, Gümüş AB. İfertilite: umutsuzluk perspektifinden bir inceleme. Psikiyatri Hemşireliği Dergisi 2014; 5(1): 9-16.

8. Karaca A, Ünsal G. İnfertil kadınların infertiliteye bağl yaşadikları stres düzeyi ve etkileyen faktörler. Hemșirelikte Eğitim ve Araştırma Dergisi 2015; 12(2): 126-132.

9. Competences: specialist competences for fertility nurses [Internet]. Royal College of Nursing; 2011; Erişim tarihi: 25.12.2017; Erişim adresi: www.rcn.org.uk/direct, London, UK.

10. Boston IVF Body-mind program [Internet]. Erişim tarihi: 25.12.2017; Erişim adresi: https://www.bostonivf.com.

11. Domar AD. The mind/body program for infertility. Fertility Today Magazine 2008; 3(1): 20.

12. The FIGO fertility tool box [Internet]. International Federation of Gyneacologic and Obstetrics. Erişim tarihi: 25.12.2017; Erişim adresi: http://www.figo.org/news/resources/FIGO_Fertility_Tool_Box

13. Infertility counseling and fertility hypnosis [Internet]. Corpus Christi Counseling and Life Coaching. Erisim tarihi: 25.12.2017; Erişim adresi: http://www.cathyarmstronglpc.com/ InfertilityCounselingandFertilityHypnosis.

14. Eastburn Hypnotherapy Center [Internet Erişim tarihi: 25.12.2017.]; Erișim adresi: http://hypnodenver.com.

15. Gilbert S. Fertility Support Program. Scottsdale, Arizona, USA; 2013.

16. Köroğlu E. Bilişsel-Davranışçı Terapiler/Temel Kavramlar Temel Yaklaşımlar. HYB Yayıncılık, 2.Baskl. Ankara; 2011.

17. Braham JB. Managing Stres/Keeping Calm Under Fire. (Çeviren: V.G., Diker). Stres Yönetimi/Ates Altında Sakin Kalabilmek. 2.Baskl. Hayat Yayıncılık: İstanbul; 2002.

18. Campagne DM. Should fertilization treatment start with reducing stress? Human Reproduction 2006; 21(7): 1651-1658.

19. Gordon JD \& Speroff L. Clinical Gynecologic Endocrinology and Infertility. (Çeviren: A.Z., Ișık\& K, Vicdan.) Klinik Jinekolojik Endokrinoloji ve İnfertilite. Nobel Matbaacllik: İstanbul; 2003.

20. Strauss JF \& Barbieri RL. Yen and Jaffe's Reproductive Endocrinology. (Çeviri editörü: S, Günalp.) Yen\&Jaffe Üreme Endokrinolojisi. Güneș Kitabevi: Ankara; 2006.

21. Whirledge S, Cidlowski JA. Glucocorticoids, Stress, and Fertility. Minerva Endocrinology 2010; 35(2): 109-125.

22. Khalsa HK. Yoga: An adjunct to infertility treatment. Complementary\&Alternative Medicine 2003; 1(1): 46-51. 